\title{
SISTEM INFORMASI PEMILIHAN TEMPAT WISATA MENGGUNAKAN METODE WEIGHTED PRODUCT
}

\author{
Anindya Khrisna Wardhani ${ }^{1}$, Arlieza Anindyaputri ${ }^{2}$ \\ ${ }^{1,2}$ Universitas Diponegoro \\ Email: ${ }^{1}$ nindywardhani77@gmail.com, ${ }^{2}$ ichaputri9999@gmail.com
}

(Naskah masuk: 9 Desember 2020, diterima untuk diterbitkan: 30 Desember 2020)

\begin{abstract}
Abstrak
Seiring dengan banyaknya tempat wisata, membuat masalah bagi wisatawan yang ingin memilih restoran. Hal ini bahkan dapat mengambil banyak waktu karena wisatawan dihadapkan pada banyak pilihan dan kurangnya informasi lengkap mengenai tempat wisata tersebut. Oleh karena itu, diperlukan sistem pendukung keputusan untuk membantu wisatawan dalam memilih tempat wisata. Dalam menentukan pemilihan tempat wisata menggunakan metode Weighted Product diperlukan beberapa kriteria menentukan tempat wisata yaitu jarak dari pusat kota, harga tiket masuk dan fasilitas. Sistem pemilihan lokasi wisata dengan metode weighted product diimplementasikan dalam sistem berbasis ponsel. Aplikasi ponsel dibuat untuk memudahkan admin dan pengguna memilih tempat wisata dengan proses yang memasukkan beberapa kriteria yang diinginkan oleh pengguna. Aplikasi ini juga di tambahkan google maps, sehingga pengguna langsung bisa mengetahui tempat wisata yang sudah menjadi pilihannya. Sistem informasi untuk memilih tempat wisata menggunakan weighted product dapat berjalan dengan baik. Pada pengujian black box, sistem dapat berjalan sesuai yang diharapkan. Pada pengujian beta, diperoleh kesimpulan bahwa sistem yang dibangun berfungsi sesuai dengan yang diinginkan user dengan skor $78,29 \%$
\end{abstract}

Kata kunci: weighted product, sistem pendukung keputusan, sistem informasi,

\section{INFORMATION SYSTEMS FOR SELECTION OF TOURISM USING A PRODUCT LIMITED METHOD}

\begin{abstract}
Along with the many tourist attractions, it creates problems for tourists who want to choose a restaurant. It can even take a lot of time because tourists are faced with many choices and a complete lack of information about these tourist attractions. Therefore, a decision support system is needed to assist tourists in choosing tourist attractions. In determining the choice of tourist attractions using the Weighted Product method, several criteria are needed to determine tourist attractions, namely the distance from the city center, entrance ticket prices and facilities. The tourist location selection system using the weighted product method is implemented in a mobilebased system. The mobile application is made to make it easier for admins and users to choose tourist attractions with a process that includes several criteria desired by the user. This application is also added with google maps, so that users can immediately find out the tourist attractions that have become their choice. The information system for choosing tourist attractions using weighted products can work well. In black box testing, the system can run as expected. In beta testing, it is concluded that the system built functions according to what the user wants with a score of $78.29 \%$.
\end{abstract}

Keywords: weighted product, decision support system, information system

\section{PENDAHULUAN}

Pariwisata merupakan salah satu kegiatan yang digemari oleh banyak kalangan pada saat ini, bahkan dapat dikatakan bahwa pariwisata merupakan salah satu kebutuhan yang penting bagi banyak orang, terutama menyangkut kegiatan sosial ekonomi yang dipandang sebagai salah satu industri pariwisata yang prospektif di masa yang akan datang (Pareira dkk., 2014). Industri pariwisata memiliki sektor pendapatan yang sangat besar dampaknya. Sebagai salah satu kegiatan yang diminati oleh masyarakat, hal ini membuat setiap kota berlomba-lomba untuk terus memperbaiki, meningkatkan sektor pariwisatanya dan memberikan teknologi informasi objek wisata dalam bentuk sistem. 
Pariwisata saat ini sedang menarik diberbagai kalangan. Masyarakat berbagi info melalui media sosial dengan mengunggah foto objek wisata (Buku Media Semarang, 2017). Adapun kendala masyarakat dalam pencarian objek wisata di suatu kota yang di kunjungi dari segi jarak, fasilitas yang ada di tempat wisata dan harga tiket masuk yang belum diketahui informasinya di dalam media sosial.

Adanya suatu teknologi sistem yang dapat mengetahui segala sesuatu tentang objek wisata secara cepat dan tepat, diharapkan dapat membantu wisatawan di dalam menentukan daerah tujuan wisata yang ingin di kunjunginya sesuai dengan kebutuhan. Untuk mendukung peningkatan objek wisata dan mengatasi permasalahan dalam memberikan keputusan maka digunakan metode decision support system. Decision support system merupakan suatu sistem yang berbasis komputer yang ditujukan untuk membantu mengambil keputusan dengan memanfaatkan data dan model tertentu untuk memecahkan berbagai persoalan yang tidak terstruktur (Sudyatmika dkk., 2015). Pada Decision support system, terdapat beberapa metode dalam menyelesaikan permasalahan ini yaitu salah satunya metode Weighted Product.

Metode weighted product diketahui lebih teliti dikarenakan metode weighted product memanfaatkan perkalian dari nilai rating kinerja yang dipangkatkan dengan nilai bobot yang telah diperbaiki sehingga urutan ranking. Hal ini menjadikan informasi perankingan yang diberikan lebih tepat dengan hasil yang spesifik dan memiliki rata-rata waktu eksekusi yang lebih cepat (Febrianto dkk., 2017). Metode weighted product digunakan untuk perhitungan perankingan beberapa tempat wisata berdasarkan kriteria yang diinginkan oleh konsumen yaitu kategori wisata, jarak, harga tiket masuk dan fasilitas.

\section{METODE}

\subsection{Weighted Product}

Weighted Product adalah metode penyelesaian dengan menggunakan perkalian untuk menghubungkan nilai atribut, di mana nilai harus dipangkatkan dulu dengan bobot atribut yang bersangkutan. Proses ini sama halnya dengan proses normalisasi (Febrianto dkk., 2017). Preferensi untuk alternatif $\mathrm{A}_{\mathrm{i}}$ diberikansebagai berikut :

$$
S_{i}=\prod_{j=1}^{n} X_{i j}{ }^{W_{j}}
$$

dengan :

$S_{i}=$ Nilai vektor $S i$

$X_{i j}=$ Nilai alternatif terhadap kriteria

$W_{j}=$ Pangkat bobot bernilai positif untuk atribut keuntungan, dan bernilai negatif untuk atribut biaya.

$\mathrm{i}=$ alternatif di mana nilai dari $\Sigma W_{j}=1 . W_{j}$ adalah pangkat bernilai positif untuk atribut keuntungan, dan bernilai negatif untuk atribut biaya. Sementara untuk menghitung nilai preferensi relatif dari setiap alternatif, diberikan persamaan sebagai berikut:

$$
V_{i}=\frac{\prod_{j=1}^{n} X_{i j}{ }^{w_{j}}}{\prod_{j=1}^{n}\left(X_{j}^{*}\right)^{W_{j}}} ; \text { dengan } i=1,2, \ldots, m .(2)
$$

dengan :

$V_{i}=$ Nilai preferensi alternatif

$X_{i j}=$ Nilai atribut alternatif

$W_{j}=$ Nilai bobot Kriteria

$\mathrm{X}_{\mathrm{j}}^{*}=$ Banyaknya nilai kriteria yang telah dinilai pada vektor $\mathrm{S}$.

Secara singkat, prosedur dari metode WP adalah sebagai berikut:

1. Melakukan perhitungan bobot terlebih dahulu agar total bobot $\Sigma W_{j}=1$. Caranya dengan membagi nilai bobot dengan penjumlahan seluruh bobot.

2. Mengalikan seluruh atribut untuk sebuah alternatif dengan bobot sebagai pangkat positif untuk atribut keuntungan dan bobot pangkat negatif pada atribut biaya disebut vektor $S_{i}$.

3. Hasil perkalian dijumlahkan untuk menghasilkan nilai pada setiap alternatif.

4. Melakukan pembagian antara $S i$ dan hasil penjumlahan $S_{i}\left(\Sigma S_{i}\right)$ yang akan menghasilkan nilai preferensi $V_{i}$.

\subsection{Metode Penelitian}

Jenis data yang digunakan dalam penelitian ini adalah:

1. Data primer, merupakan data yang diperoleh dari objek penelitian, sebagai berikut: daftar tempat wisata, harga tiket masuk, jarak dan fasilitas.

2. Data sekunder adalah data yang diperoleh dari studi pustaka, buku referensi, dan penelusuran internet.

Metode pengumpulan data yang dilakukan dalam penelitian ini adalah:

1. Observasi: pengumpulan data melalui observasi dan wawancara langsung dengan wisatawan.

2. Studi Pustaka: mengumpulkan literatur pendukung penelitian, baik dari buku referensi maupun dari internet.

Data penelitian yang digunakan untuk penelitian adalah data yang terdapat di Kota Semarang sebanyak 45 data.

\section{HASIL DAN PEMBAHASAN}

\subsection{Perhitungan Metode Weighted Product}

Dalam proses perankingan metode weighted produc, data kriteria yang digunakan adalah kategori tempat wisata, harga tiket masuk dan jarak. Rincian 
kriteria yang digunakan dalam proses metode weighted product dapat dilihat dari tabel sebagai berikut:

\section{Kriteria Kategori Wisata}

Pada menu kriteria, ketegori wisata dibagi menjadi 6 yaitu wisata tour desa, pendidikan, air religi, alam, warisan budaya/history dan buatan. Pembagian kategori menu ditunjuk pada tabel 1 .

\begin{tabular}{lc}
\multicolumn{2}{c}{ Tabel 1 Kategori Menu } \\
\hline \multicolumn{1}{c}{ Kategori } & Kode \\
\hline Wisata Tour Desa & 1 \\
\hline Wisata Pendidikan & 2 \\
\hline Wisata Air & 3 \\
\hline Wisata Religi & 4 \\
\hline Wisata Alam & 5 \\
\hline Wisata Warisan Budaya/history & 6 \\
\hline Wisata Buatan & 7 \\
\hline
\end{tabular}

Sebagai contoh, user menginginkan kategori wisata alam. Maka data yang akan diolah menggunakan metode weighted product adalah data dari wisata alam wisata alam.

\section{Kriteria Harga}

Kriteria harga yang digunakan merupakan range harga berdasarkan kategori wisata.

\begin{tabular}{cllc}
\multicolumn{3}{c}{ Tabel 2 Range Harga } \\
\hline No & $\begin{array}{c}\text { Kategori } \\
\text { Harga }\end{array}$ & \multicolumn{1}{c}{ Range Harga } & Kode \\
\hline $\mathbf{1}$ & Free & $=\mathrm{Rp} \mathrm{0}$ & 1 \\
\hline $\mathbf{2}$ & Murah & $\begin{array}{l}\mathrm{Rp} 100-\mathrm{Rp} \\
15.000\end{array}$ & 2 \\
\hline $\mathbf{3}$ & Sedang & $\begin{array}{l}\mathrm{Rp} 15.100-\mathrm{Rp} \\
24.000\end{array}$ & 3 \\
\hline $\mathbf{4}$ & Mahal & $>\mathrm{Rp} 24.100$ & 4 \\
\hline
\end{tabular}

\section{Kriteria Fasilitas}

Kriteria fasilitas yang tertera pada tabel 3 merupakan fasilitas yang terdapat pada tempat wisata tersebut.

\begin{tabular}{ccc}
\multicolumn{3}{c}{ Tabel 3 Range Harga } \\
\hline No & Kategori & Kode \\
\hline $\mathbf{1}$ & Tidak ada Fasilitas & 0 \\
\hline $\mathbf{2}$ & Free Wifi & 2 \\
\hline $\mathbf{3}$ & Toilet & 1 \\
\hline $\mathbf{4}$ & Tempat Ibadah + Wifi & 4 \\
\hline $\mathbf{5}$ & Tempat Ibadah + Toilet & 3 \\
\hline $\mathbf{6}$ & Tempat Ibadah + Toilet + \\
Restoran & 5 \\
\hline $\mathbf{7}$ & $\begin{array}{c}\text { Tempat Ibadah + Toilet }+ \\
\text { Restoran + Wifi }\end{array}$ \\
\end{tabular}

\section{Kriteria Jarak}

Berdasarkan data lokasi tempat wisata yang ada di Semarang, range jarak dibagi menjadi tiga yaitu dekat, sedang dan jauh dari pusat kota. Range jarak ditunjukkan pada tabel 4 .
Tabel 4 Range Jarak

\begin{tabular}{cllc}
\hline No & Jarak & \multicolumn{1}{c}{ Range Jarak } & Kode \\
\hline $\mathbf{1}$ & Dekat & $<3,8 \mathrm{~km}$ & 1 \\
\hline $\mathbf{2}$ & Sedang & $3,8 \mathrm{~km}-8,6 \mathrm{~km}$ & 2 \\
\hline $\mathbf{3}$ & Jauh & $>8,7 \mathrm{~km}$ & 3 \\
\hline
\end{tabular}

Berdasarkan kriteria diatas, dapat diambil contoh ketika wisatawan ingin memilih tempat wisata dengan kriteria kategori wisata air, jarak yang dekat, dan harga murah. Maka perhitungan dalam metode weighted product menggunakan sample data yang ditunjukkan pada tabel 5 .

\begin{tabular}{cccc}
\multicolumn{4}{c}{ Tabel 5 Range Jarak } \\
\hline No & Alternatif & \multicolumn{2}{c}{ Kriteria } \\
\cline { 3 - 4 } & & $\begin{array}{c}\text { Jarak } \\
(\mathbf{k m})\end{array}$ & $\begin{array}{c}\text { Harga Tiket } \\
\text { Masuk }\end{array}$ \\
\hline $\mathbf{1}$ & Water Blaster & 6.9 & $\operatorname{Rp~60.000}$ \\
\hline $\mathbf{2}$ & Waduk Jatibarang & 13.5 & $\operatorname{Rp~} 2.500$ \\
\hline $\mathbf{3}$ & Pantai Maron & 10.2 & $\operatorname{Rp~5.000}$ \\
\hline $\mathbf{4}$ & Pantai marina & 7.6 & $\operatorname{Rp~3.000}$ \\
\hline $\mathbf{5}$ & Banjir Kanal Barat & 4.3 & 0
\end{tabular}

Tabel 6 Rating kecocokan dari setiap alternatif pada setiap kriteria

\begin{tabular}{ccccc}
\hline No & Alternatif & \multicolumn{3}{c}{ Kriteria } \\
\cline { 3 - 5 } & $\begin{array}{c}\text { Jarak } \\
(\mathbf{k m})\end{array}$ & Fasilitas & $\begin{array}{c}\text { Harga } \\
\text { Tiket } \\
\text { Masuk }\end{array}$ \\
\hline $\mathbf{1}$ & $\begin{array}{c}\text { Water } \\
\text { Blaster }\end{array}$ & 2 & 6 & 4 \\
\hline $\mathbf{2}$ & $\begin{array}{c}\text { Waduk } \\
\text { Jatibarang }\end{array}$ & 3 & 1 & 2 \\
\hline $\mathbf{3}$ & $\begin{array}{c}\text { Pantai } \\
\text { Maron }\end{array}$ & 3 & 1 & 2 \\
\hline $\mathbf{4}$ & $\begin{array}{c}\text { Pantai } \\
\text { marina }\end{array}$ & 2 & 6 & 2 \\
\hline $\mathbf{5}$ & $\begin{array}{c}\text { Banjir Kanal } \\
\text { Barat }\end{array}$ & 2 & 1 & 1 \\
\hline
\end{tabular}

Bobot preferensi sebagai berikut: $W=(\mathbf{4 , 4 , 5 )}$

Keterangan besarnya bobot:

5 = sangat penting,

$4=$ penting,

$3=$ cukup penting,

2 = tidak begitu penting,

$1=$ tidak penting

Bobot tersebut merupakan bobot yang diberikan pada jarak, fasilitas dan harga tiket masuk. Sebelumnya dilakukan perbaikan bobot terlebih dahulu dari bobot preferensi sebelumnya yaitu $\mathrm{W}=$ $(4,4,5)$.

$\mathrm{W}_{\mathrm{j}}$ merupakan $\mathrm{W}$ index ke j. Sehingga untuk W1 yaitu 4 , W2 yaitu 4 dan seterusnya. Sedangkan $\Sigma W_{j}$ merupakan jumlah dari W. Jadi untuk perbaikan bobot W1 menjadi:

$\mathrm{W} 1=\frac{4}{4+4+5}=0,31$
$\mathrm{~W} 2=\frac{4}{4+4+5}=0,31$
$\mathrm{~W} 3=\frac{5}{4+4+5}=0,38$ 
Tabel 6 Hasil Perbaikan Bobot

\begin{tabular}{cc}
\hline & Weight \\
\hline W1 & 0.31 \\
\hline W2 & 0.31 \\
\hline W3 & 0.38 \\
\hline
\end{tabular}

Tahap selanjutnya adalah menentukan nilai vektor $\mathrm{S}$ dengan memangkatkan dan kalikan nilai masingmasing kriteria tersebut dengan bobot yang sudah diperbaiki sebelunya.

Perhitungan Vektor S adalah sebagai berikut :

$\mathrm{S} 1=\left(2^{-0,31}\right)\left(6^{0,31}\right)\left(4^{-0,38}\right)=0.8429$

$\mathrm{S} 2=\left(3^{-0,31}\right)\left(1^{0,31}\right)\left(2^{-0,38}\right)=0.546$

$\mathrm{S} 3=\left(3^{-0,31}\right)\left(1^{0,31}\right)\left(2^{-0,38}\right)=0.546$

$\mathrm{S} 4=\left(2^{-0,31}\right)\left(6^{0,31}\right)\left(2^{-0,38}\right)=1.0796$

$\mathrm{S} 5=\left(2^{-0,31}\right)\left(1^{0,31}\right)\left(1^{-0,38}\right)=1.4058$

Langkah selanjutnya menentukan nilai vector yang akan digunakan yaitu menghitung Preferensi $\left(\mathrm{V}_{\mathrm{i}}\right)$ untuk perengkingan. Hasil dari proses Preferensi (Vi) adalah sebagai berikut:

$$
\begin{aligned}
& \mathrm{V} 1=\frac{0.8429}{0.8429+0.546+0.546+1.0796+1.4058}=\frac{0.8429}{4.4203}=0.1907 \\
& \mathrm{~V} 2=\frac{0.4685}{0.8429+0.546+0.546+1.0796+1.4058}=\frac{0.546}{4.4203}=0.1235 \\
& \mathrm{~V} 3=\frac{0.4685}{0.8429+0.546+0.546+1.0796+1.4058}=\frac{0.546}{4.4203}=0.1235 \\
& \mathrm{~V} 4=\frac{0.8429+0.546+0.546+1.0796+1.4058}{0.8429+0.546+0.546+1.0796+1.4058}=\frac{1.0796}{4.4203}=0.2096 \\
& \mathrm{~V} 5=\frac{0.8294}{0.8429+0.546+0.546+1.0796+1.4058}=\frac{1.4058}{4.4203}=0.1876
\end{aligned}
$$

\subsection{Implementasi Sistem}

Implementasi interface pada sistem dibangun di perangkat mobile. Berikut ini beberapa tampilan interface yang telah diimplementasikan oleh sistem.

\section{Menu Utama}

Pada bagian ,menu utama terdapat pengenalan tempat wisata yang ada di Kota Semarang. Dalam menu utama terdapat sebuah tombol "Mau Wisata Ke mana ?" serta menu deskripsi wisata berdasarkan kategori-kategori yang tersedia. Tampilan menu utama ditunjukkan pada gambar 1 dan gambar 2

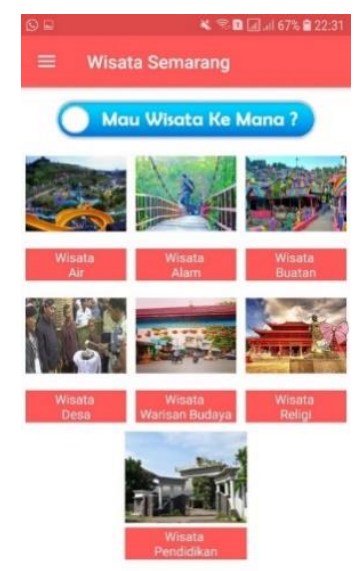

Gambar 1 Interface Menu Utama

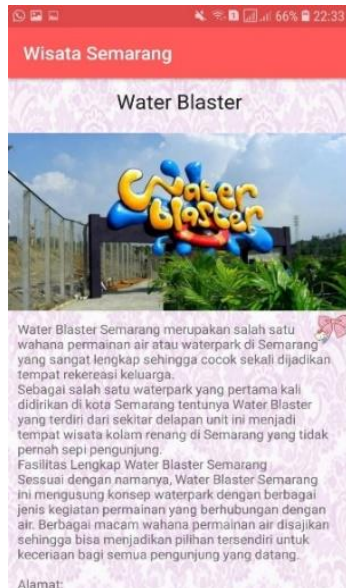

Gambar 2 Interface Menu Deskripsi Wisata

\section{Menu "Mau Wisata Ke mana"}

Pada menu ini, difungsikan untuk menentukan kriteria - kriteria yang diinginkan wisatawan untuk diolah menggunakan algoritma weighted product agar mendapatkan output rekomendasi lokasi wisata. Tampilan menu tersebut ditunjukan pada gambar 3 .

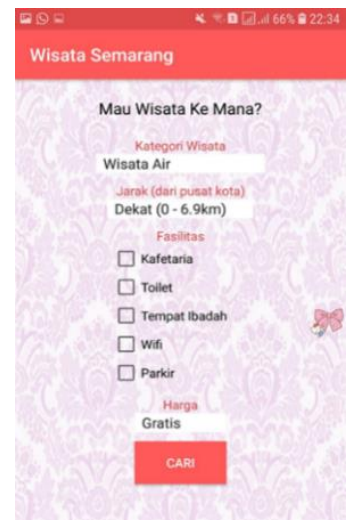

Gambar 3 Interface Menu "Mau Wisata Ke mana"

Setelah wisatawan input kriteria tempat wisata yang diinginkan, sistem akan memberikan output beberapa rekomendasi lokasi wisata. Menu hasil rekomendasi ditunjukan pada gambar 4 .

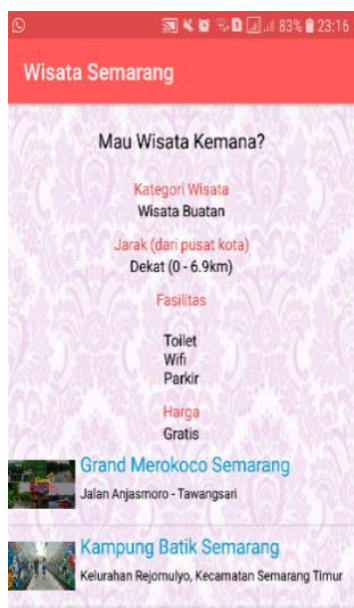

Gambar 4 Interface Menu Hasil Rekomendasi 


\subsection{Pengujian Black Box}

Hal terpenting dari pengujian suatu system adalah menemukan kesalahan-kesalahan atau kekurangan yang ada pada system. Pengujian bermaksud untuk mengetahui perangkat lunak yang dibuat sudah memenuhi kriteria yang sesuai dengan tujuan perancangan perangkat lunak tersebut.

Salah satu metode dalam pengujian untuk menguji suatu system adalah metode blackbox. Pengujian black box memiliki fokus pada spesifikasi fungsional dari perangkat lunak, spesifikasi testing dan input atau output testing. Pengujian blackbox digunakan untuk menguji sebuah sistem baru dan mencakup error yang akan terjadi.

Pengujian black box dilakukan untuk memberikan informasi bahwa yang dilakukan system untuk memastikan input pada sistem yang akan menjalankan proses tepat serta dapat menghasilkan output yang sesuai dengan rancangan yang diinginkan. Berdasarkan pengujian black box, sistem dapat berjalan sesuai yang diharapkan.

\subsection{Pengujian Beta}

Pengujian Beta adalah pengujian yang dilakukan dengan cara dimana system diuji langsung ke lapangan. Cara pengujian beta yaitu dengan membuat kuesioner mengenai kepuasan wisatawan kepada system dalam memberikan rekomendasi tempat wisata. Pada penelitian ini, kuisioner dibagikan kepada 50 orang. Kuesioner dalam pengujian beta terdiri dari 20 pertanyaan dengan menggunakan skala 1 sampai 5. Adapun ketentuan skala untuk setiap pertanyaan ditunjukkan pada tabel 4.17 (Ependi, 2015).

\begin{tabular}{ccc}
\multicolumn{3}{c}{ Tabel 7 Skala Kuisioner } \\
\hline Skala Jawaban & Keterangan & Skor \\
\hline SS & Sangat setuju & 5 \\
\hline S & Setuju & 4 \\
\hline C & Cukup & 3 \\
\hline TS & Tidak Setuju & 2 \\
\hline STS & Sangat tidak setuju & 1 \\
\hline
\end{tabular}

Data yang diperoleh dari pemberian kuesioner kepada responden dapat dianalisis dengan menghitung rata-rata jawaban berdasarkan scoring setiap jawaban dari responden, analisis yang dapat dilakukan yaitu sebagai berikut.

Jumlah skor ideal untuk seluruh item

$=5 \times$ jumlah responden

$=5 \times 50$

$=250$

Rata-rata skor dalam persentase $=$ ( jumlah skor : jumlah skor ideal) $\times 100 \%$

Daftar pernyataan yang digunakan dalam pengujian beta dapat dilihat pada tabel 8 .
Tabel 8 Kuisioner

\begin{tabular}{|c|c|c|c|c|c|}
\hline No & Daftar Pernyataan & STS & TS & C S & SS \\
\hline & & 1 & 2 & 34 & 5 \\
\hline 1 & Anda suka berwisata. & & & & \\
\hline 2 & $\begin{array}{l}\text { Anda pernah kesulitan } \\
\text { mencari informasi mengenai } \\
\text { tempat wisata. }\end{array}$ & & & & \\
\hline 3 & $\begin{array}{l}\text { Anda pernah mencari } \\
\text { informasi mengenai tempat } \\
\text { wisata menggunakan telepon } \\
\text { selular. }\end{array}$ & & & & \\
\hline 4 & $\begin{array}{l}\text { Menurut anda, mencari } \\
\text { informasi tempat wisata } \\
\text { menggunakan telepon selular } \\
\text { sangatlah penting. }\end{array}$ & & & & \\
\hline 5 & $\begin{array}{l}\text { Anda membutuhkan } \\
\text { rekomendasi tempat wisata } \\
\text { dari sebuah sistem. }\end{array}$ & & & & \\
\hline 6 & $\begin{array}{lr}\text { Anda membutuhkan sebuah } \\
\text { sistem yang } & \text { memudahkan } \\
\text { anda dalam } & \text { melakukan } \\
\text { pencarian } & \text { berdasarkan } \\
\text { pengelompokan } & \text { kategori } \\
\text { tempat wisata. } & \\
\end{array}$ & & & & \\
\hline 7 & $\begin{array}{l}\text { Dalam sistem pemilihan } \\
\text { tempat wisata ini } \\
\text { memudahkan anda dalam } \\
\text { melakukan pencarian } \\
\text { berdasarkan kategori wisata, } \\
\text { harga, fasilitas dan jarak dari } \\
\text { pusat kota. }\end{array}$ & & & & \\
\hline 8 & $\begin{array}{l}\text { Anda mendapatkan informasi } \\
\text { mengenai tempat wisata di } \\
\text { Kota Semarang menggunakan } \\
\text { sistem ini. }\end{array}$ & & & & \\
\hline 9 & $\begin{array}{l}\text { Sistem ini menampilkan } \\
\text { perankingan rekomendasi } \\
\text { alternatif tempat wisata sesuai } \\
\text { dengan kriteria yang anda } \\
\text { inginkan. }\end{array}$ & & & & \\
\hline 10 & $\begin{array}{l}\text { Sistem ini menampilkan } \\
\text { pengelompokan kategori } \\
\text { tempat wisata sesuai yang } \\
\text { diinginkan wisatawan. }\end{array}$ & & & & \\
\hline 11 & $\begin{array}{lr}\text { Anda } & \text { mendapatkan } \\
\text { rekomendasi } & \text { sesuai yang } \\
\text { anda inginkan pada sistem ini. }\end{array}$ & & & & \\
\hline 12 & $\begin{array}{l}\text { Anda dapat dengan mudah } \\
\text { mencari berdasarkan kategori } \\
\text { tempat wisata pada sistem ini } \\
\text { dengan mudah. }\end{array}$ & & & & \\
\hline 13 & $\begin{array}{l}\text { Dengan adanya sistem ini, } \\
\text { anda tidak membutuhkan } \\
\text { waktu yang lama dalam } \\
\text { pemilihan tempat wisata. }\end{array}$ & & & & \\
\hline 14 & $\begin{array}{l}\text { Dengan adanya sistem ini, } \\
\text { anda dapat mengestimasi } \\
\text { biaya harga tiket masuk } \\
\text { tempat wisata. }\end{array}$ & & & & \\
\hline 15 & $\begin{array}{l}\text { Fitur pada menu utama } \\
\text { membuat anda lebih } \\
\text { memahami tentang tempat } \\
\text { wisata yang ada di Kota } \\
\text { Semarang. }\end{array}$ & & & & \\
\hline
\end{tabular}

Berdasarkan hasil dari pengujian beta, dapat disimpulkan bahwa system yang dibangun dapat berfungsi dengan baik dan dapat memberikan rekomendasi seperti yang diharapkan oleh wisatawan dengan skor $78.29 \%$. 


\section{KESIMPULAN DAN SARAN \\ 4.1 KESIMPULAN}

Berdasarkan dari hasil dan pembahasan, menunjukan bahwa metode weighted product dapat diimplementasikan untuk menentukan pemilihan tempat wisata dapat menentukan rekomendasi yang sesuai dengan kriteria wisatawan. Selain memberikan rekomendasi, system ini dapat memberi informasi berupa data tempat wisata seperti alamat, fasilitas serta harga dari tiket masuk wisata tersebut.

Pada pengujian blackbox, system ini dapat digunakan dengan baik atau dapat berjalan sesuai dengan yang diharpkan. Pada pengujian beta, yang dilakukan kepada 50 orang wisatawan, diperoleh skor $78,29 \%$. Hal ini berarti sistem dapat sesuai dengan apa yang diharapkan oleh wisatawan.

\subsection{SARAN}

Dalam penelitian ini tidak menggunakan jarak berdasarkan jarak user menuju tempat wisata. Hal ini dapat mempermudah wisatawan dalam pemilihan tempat wisata dengan lebih akurat. Selain itu, system ini menggunakan perangkat lunak berbasis aplikasi yang hanya dapat digunakan pada platform android. Saran dalam penelitian ini adalah untuk menggunakan system berbasis website sehingga dapat memudahkan wisatawan tanpa harus menginstall aplikasi.

\section{DAFTAR PUSTAKA}

A. Anindyaputri, C. E. Widodo, J. E. Suseno, “An Integrated Information System for Selection of Areas Tourist Sites Using Clustering and Electre Methods," Proc. Atlantis Press Vol.165, pp.71-75, July 2018.

A. K. Wardhani, C. E. Widodo, J. E. Suseno, "Information System for Culinary Product Selection Using Clustering K-Means and Weighted Product Method," Proc. Atlantis Press Vol.165, pp.18-22, July 2018.

A. K. Wardhani, E. Lutfina, "Application Culinary Decision Support System in Kudus City with Weighted Product Method Based on Mobile Phone," Journal of Computer Science an Engineering, Vol.1, February 2020.

A. Y. Wicaksono, R. Rismanto, and A. Prasetyo, "Pengembangan Aplikasi Sistem Informasi Rekomendasi Tempat Wisata di Kota Batu Menggunakan Metode Electre [Development of the Information System Application of Tourist Sites Recommendation in Batu City using Electre Method]," vol. 3, pp. 32-38, 2017.

Febrianto, R., dan Suharsono N.T., Analisis perbandingan metode simple additive weighting dan metode weighted product untuk menentukan bonus karyawan, Jurnal LPKIA, vol 1, 2017
K. Cao, and Z. Yang, "A study of e-commerce adoption by tourism websites in China," J. Int. of Destin. Mark. \& Manage., vol. 5, pp. 283-289, 2016

Pareira, O., Santoso, A. J., dan Ardanari, P., Sistem pendukung keputusan pemilihan tempat wisata di timor leste dengan metode electre. Journal Dili Institute of Technology, Universitas Atma Jaya Yogyakarta, hal 1015,2014

Sudyatmika, I W. A., Darmawiguna, I G. M., dan Wirawan, I M. A., Pengembangan Sistem Pendukung Keputusan Berbasis Android Untuk Penentuan Daerah Tujuan Wisata Di Bali Dengan Menggunakan Metode Fuzzy Tahani, Jurnal Teknik Informatika., vol. 4, hal 20-27, 2015 